\title{
Estonian Science Teacher Beliefs about Competence-based, Science E-testing
}

\author{
Triin Rosin*, Katrin Vaino, Regina Soobard, and Miia Rannikmäe \\ Centre for Science Education, Faculty of Science and Technology, University of Tartu, Estonia
}

*Corresponding Author: triin.rosin@ut.ee

\section{ABSTRACT}

Competence-based, science e-testing (CBSeT) is a novel external assessment tool which provides feedback to science teachers about their students' competence-based skills, thereby giving relevant assessment information which teachers could potentially use in their teaching practice. The aim of this study was to determine the extent to which teachers' existing beliefs toward CBSeT enabled them to use the received CBSeT feedback in their practice. Semi-structured interviews were conducted with eleven science teachers from selected schools which took part in an CBSeT pilot program. The findings revealed that most teachers believed the feedback provided adequate assessment information about the level of students' actual competences and gave general guidelines to support their further teaching and students' learning. At the same time, they perceived that the CBSeT feedback was currently lacking an accountability function, which would make students more responsible for their learning and provide feedback on the effectiveness of their own teaching. Despite the teachers' generally positive attitudinal beliefs toward CBSeT, several constraints to operationalizing the feedback in the classroom were identified. Based on these findings, the paper suggests ways to facilitate further implementation of CBSeT feedback in the classroom.

KEY WORDS: assessment; competence-based science e-testing; feedback; teacher beliefs

\section{INTRODUCTION}

$\mathbf{E}$ ducational assessment, as a set of methodologies and processes used to design, collect, analyze, and interpret evidence of student learning (Brown, 2017), has changed over the last decades, putting more emphasis on understanding every student's learning potential (Black, 2000; Brookhart, 2010). In place of teaching and then assessing pure science content knowledge after teaching a unit, science teachers are expected to promote a wider range of competences related to science learning and, for example, assess students' ability to solve socially relevant problems using acquired knowledge (Alt, 2018). As students tend to learn what is assessed (Biggs, 1995), science teachers are expected to think critically about what and how to assess their students.

To support Estonian science teachers in adopting more student-centered teaching and aligning assessment strategies to target students' gaining of wider scientific competences, as stated in the national curriculum (Ministry of Education and Research, 2014a), a theoretical competence-based, science e-testing (CBSeT) model, together with a respective feedback system, was developed (Rannikmäe et al., 2019). The purpose of CBSeT was to support a more competencebased teaching approach by providing teachers with appropriate feedback. This was seen as important, because the structure of previous national science examinations (Rannikmäe et al., 2017) did not provide information about students' achievement in specific competences, nor was emphasis placed on scientific competences other than content knowledge.

The use of assessment outcomes in teaching depends on how teachers understand the purpose of the received feedback (Brown, 2017). In interpreting assessment information, teacher beliefs act as filters, impacting on their interpretation of the curriculum and the design of lesson plans (Fives and Buehl, 2012). Furthermore, teacher beliefs have been found to hinder their adoption of new knowledge (Brown, 2004; Brown and Harris, 2009; Goodson et al., 2006). Thus, exploring how teachers interpret assessment information, such as that provided by $\mathrm{CBSe}$, is meaningful, not only for identifying teacher beliefs but also in offering appropriate guidance to teachers.

Based on the above, the aim of this study was to recognize the extent to which teachers' existing beliefs toward CBSeT enabled them to use the received feedback in their practice to promote wider scientific competences in students.

The specific research questions were:

1. What beliefs do teachers hold regarding the purposes of feedback received from CBSeT?

2. What beliefs do teachers hold about CBSeT in science subjects and the development of wider scientific competences in students which CBSeT intends to promote? 


\section{Theoretical Background}

\section{Assessment}

The nature of assessment and the relationship between formative (FA) and summative assessment (SA) has been extensively discussed in the literature (Black and Wiliam, 2009; Brown, 2017; Harlen and James, 1997; Newton, 2007; Shute, 2008). While FA aims to improve teaching and learning (Black and Wiliam, 2009; Cizek, 2010; Newton, 2007), SA is seen as more complex, serving several purposes, such as providing grades to evaluate competence and predict later success (Newton, 2007). Furthermore, questions have been raised as to whether SA can also serve formative purposes, or, alternatively, how can external assessment (which usually serves a summative purpose) be used to support teaching and learning (Harlen, 2012; Newton, 2007). Newton (2007) has pointed out that it is perhaps not as important to distinguish between the purposes of SA and FA, as to focus on the purposes of assessment more generally. Newton (2007) indicates that this purpose simply depends on how the assessment results are used.

\section{Feedback}

Feedback is the key mechanism linking assessment and teaching (Hattie and Timperley, 2007). Brown et al. (2014) suggest that the critical aspect of any assessment is the quality of the feedback and how that feedback is used to inform the teaching and learning process. According to Hattie and Timperley (2007), good feedback should address the following:

a. What are the goals?

b. What progress is being made toward the goals?

c. What activities need to be undertaken to make better progress? (p. 86)

One important source of feedback for teachers is assessment information from student testing, which, in turn, can be used to support the teaching-learning process (Bennett, 2011; Brown et al., 2014; Xiao, 2017). Such information needs to be descriptive (so-called formative), without which it is not possible to use the feedback to improve teaching (Brown, 2017; Sadler, 2010).

\section{Teachers' beliefs and practices}

The definition of "beliefs" is contested, complicated, and differs throughout literature, at times equated with attitudes, at other times with perception (Pajares, 1992). Nevertheless, teaching beliefs are argued to influence teachers' choices of teaching methods significantly (Bryan, 2012; Chen at al., 2012), as well as their assessment practices (Khan, 2000; Title, 1994).

Several studies have identified opposing teacher beliefs about the teaching approach: Often referred to as teacher-centered and student-centered (Chen et al., 2012; Fives et al., 2015; Trigwell, 2012). Fives et al. (2015) argue that teacher-centered approaches relate to a transmission teaching model, while student-centered approaches typically reflect constructivist views of teaching.
In a teacher-centered approach, the teacher controls what, when, and under what conditions the learning takes place and teaching is based primarily on the transfer of knowledge, skills, and values (Chen and Brown, 2016). In student-centered approaches, teachers are more likely to value students' ideas and encourage them to construct and develop their own knowledge (Trigwell, 2012). The student-centered approach is also related to promote scientific competences, for example, skills to create links between scientific facts, apply an understanding of new science concepts in new situations, employ creative thinking, and solve problems with socio-scientific context (Alt, 2018; Kutluca and Aaydin, 2016; Roberts and Bybee; 2014; Qureshi et al., 2016). Although teachers can simultaneously hold beliefs reflecting both, teacher-centered and student-centered approaches (Chen and Brown, 2016; Verjovsky and Waldegg, 2005), several studies, including studies carried out among Estonian science teachers, have found that teacher-centered approaches tend to dominate among teachers (Duru, 2015; Henno et al., 2017; Kask, 2009).

Changes in teachers' beliefs toward adopting contemporary learning conceptions and teaching strategies are proven to be time-consuming (Henno et al., 2017; Vaino, 2013). For example, an intervention study conducted by Vaino et al. (2013) has shown experienced teachers took three years, through several in-service sessions and trial and error experiences in the classroom, to adopt beliefs and practices toward contemporary conceptions of scientific literacy. Furthermore, according to studies by Buldur (2016) and Markic and Eilks (2013), it is possible to guide student teachers to adopt more contemporary teaching beliefs through a more extensive or longer professional development program.

Teacher beliefs have an impact on assessment. The teacher perceived purposes of assessment are related to their beliefs, on the basis of which they process information about new assessment practices and principles (Barnes et al., 2015; Brown, 2004; Brown, 2017). Brown (2008) has identified four main beliefs about the purposes of assessment, seeing these as to:

a. Improve teaching and learning (improvement). Assessment provides useful and accurate information to teachers and/ or students so they can undertake necessary changes to improve the quality of teaching and/or learning

b. Make schools and teachers accountable for their own effectiveness (school and teacher accountability). Such assessment shows the quality of the school and teacher efforts in ensuring that student achievement levels meet society's expectations

c. Make a student responsible for his or her own learning (student accountability). The assessment shows the degree to which students achieve that expected of them, shows the quality of their performance through grades and certificates awarded

d. No purpose, as the assessment is felt fundamentally irrelevant for teachers and students (irrelevance). The feedback from assessment is felt to be inaccurate and/or inappropriate and is therefore ignored. 
According to Brown et al. (2019), educational policy holds two purposes of assessment:

- To improve teaching and learning, and also

- To ensure the quality of teaching and learning.

Based on this, teachers are expected to fulfill these two purposes simultaneously. It has been shown that such ambiguity leads to a situation where teachers' beliefs can be two-fold, to use assessment to improve teaching and learning and to use an assessment that makes teachers and schools accountable for their effectiveness (Barnes et al., 2015; Bonner, 2016; Brown, 2016). In a New Zealand empirical study conducted by Brown and Harris (2009), where the official assessment policy is based on assessment for learning, school accountability is still dominant in teachers' beliefs. The same authors claimed that diversified assessment resources and support provided by teacher professional development have not been able to persuade most teachers that assessment can meet the purpose of both improvement and accountability.

Beliefs are considered good indicators for predicting people's decisions over a lifetime (Bandura, 1993), though the relationship between teacher beliefs and practices seems to be more complicated. While some studies have found a good coherence between teachers' expressed beliefs and practice (Beck et al., 2000; Jamalzadeh and Shahsavarb, 2015; Levitt, 2002; Wallace and Kang, 2004), others have not reached such confirmation (Kynigos and Argyris, 2004; Roberts et al., 2016; Sak et al., 2018; Zembylas, 2005).

The theory of planned behavior (TPB) (Ajzen, 1991; 2005; 2011) seeks to bridge the gap between stated beliefs and actual behavior by adding normative and control beliefs into a predictive model (Figure 1).

According to the model (Ajzen, 2005), the following three belief components are expected to predict, relatively well, intention, and actual behavior:

1. Attitude toward a given behavior (behavioral beliefs) reflects global, positive or negative evaluation of performing a particular behavior - the more favorable the attitude, the stronger the intention to perform

2. Subjective (normative) beliefs can be seen as a perceived attitude of significant others, but also as a global perception of social pressure to perform the given behavior; if it is perceived that significant others endorse (or disapprove of) the behavior, there a is more (or less) likelihood of performing this behavior

3. Perceived control over the given behavior (control beliefs) - whether the skills, resources, etc., are perceived to perform a given behavior; this belief component enables behavioral predictions, which are not always completely under one's own control (in Figure 1, this is illustrated by the direct link between the control beliefs and behavior). Ajzen's TPB has been successfully applied in science education to explore teacher beliefs (e.g., Vaino et al., 2013; Haney and McArthur, 2002; Heuckmann et al., 2020). Research findings (both quantitative and qualitative) support the general assumption of TPB, whereby the more positive belief structures (attitudes, capability, and context beliefs) a teacher holds toward a given behavior, the more likely it is that s/he actually executes it in practice.

\section{Context: CBSeT Pilot Project in Estonia}

The current study is part of a large-scale project conducted within the Estonian Lifelong Learning Strategy 2020 (Ministry of Education and Research, 2014b) focusing on the development of an electronic external assessment tool to stimulate competence-based teaching and assessment in schools. Schools participated in the validation of CBSeT instrument on a voluntary basis. The pre-testing of CBSeT was administered to $9^{\text {th }}$-grade students $(15-16$ years old, $\mathrm{n}=$ 1022) in 2017 and basic testing of CBSeT was administered to $9^{\text {th }}$-grade students $(15-16$ years old, $n=1022)$ in 2018 all over Estonia. CBSeT was based on a set of contextual test items, both open-ended and closed cognitive sub-items which included both subject-specific (chemistry, physics, biology, geography) and interdisciplinary competences. These competences included:

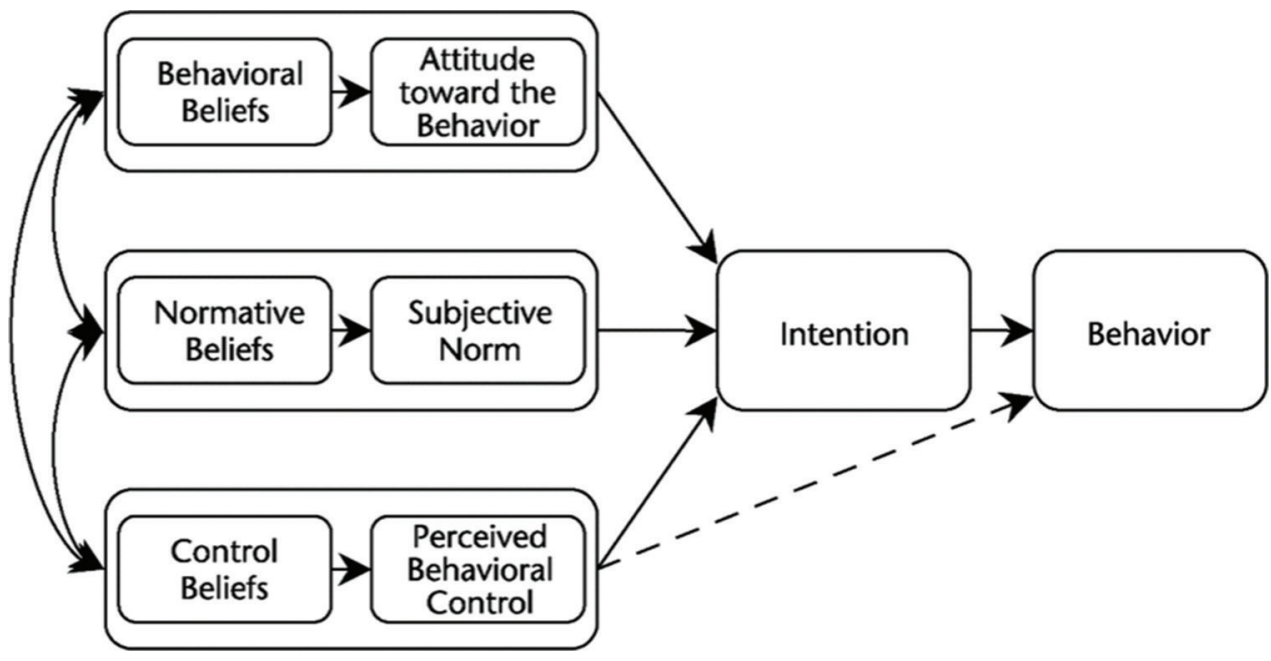

Figure 1: The Theory of Planned Behaviour (Ajzen, 2005, p. 126) 
1. Scientific content

2. Inquiry skills

3. Problem solving and decision making skills, and

4. Communication skills.

The developed format of feedback was based on a theoretical model for constructing an $\mathrm{CBSeT}$ and the use of a specific instrument (Rannikmäe et al., 2019). Based on the analysis of students' outcomes, the following were developed:

- Levels of scientific competences (baseline, average, highlevel, and excellent)

- Descriptions of the levels with respect to each competence, and

- The format of feedback to relevant stakeholders (teachers, students, schools) (amplified in Appendix 1).

Based on the developed feedback model, individual students received an interpretative description of their existing competences, plus a description of a subsequent competence level to be set as a target for the next step of learning.

\section{METHODOLOGY}

This study used a qualitative research design in order to understand teacher beliefs in-depth. The sample consisted of eleven science teachers who were interviewed using a semistructured interview approach. These teachers represented a cross-section of science teachers whose students $\left(9^{\text {th }}\right.$ grade, 15-16 years old) took part in piloting a national CBSeT study for which the first author selected the participating schools $(n=40)$. From a proposal sent to teachers to participate in the study, eleven science teachers responded positively. The background data of these teachers are shown in Table 1, who are referred to in this paper by the assigned codes - T1-T11.

\section{Data Collection}

Semi-structured interviews were conducted with each teacher individually. Each interview was supported by computer slides and printouts of simulated computer-generated feedback on the CBSeT results for his or her students (Appendix 1 for an example). The semi-structured interviews were based on the following questions:

Table 1: Teachers who participated in the interview and their background information

\begin{tabular}{lllc}
\hline Teacher & Gender & Specialty & $\begin{array}{c}\text { Teaching experience } \\
\text { (years) }\end{array}$ \\
\hline Teacher 1 & F & Physics/biology & 12 \\
Teacher 2 & F & Chemistry & 15 \\
Teacher 3 & F & Chemistry & 12 \\
Teacher 4 & M & Geography & 2 \\
Teacher 5 & F & Biology & 27 \\
Teacher 6 & F & Biology/geography & 26 \\
Teacher 7 & F & Physics/chemistry & 10 \\
Teacher 8 & M & Geography/biology & 15 \\
Teacher 9 & F & Biology/chemistry & 1 \\
Teacher 10 & M & Geography & 17 \\
Teacher 11 & M & Physics & 30 \\
\hline
\end{tabular}

1. What benefits do you perceive from information on your students' CBSeT results when you plan your further teaching?

2. What benefits do you perceive from the feedback on CBSeT results when you plan your further teaching?

3. What opinions do you hold about CBSeT and the competences assessed?

These questions alongside the slides and printout of CBSeT results guided the overall course of the interview, but for creating a more relaxed atmosphere, the teachers were encouraged to express any further thoughts on their perceptions of, and experiences with, CBSeT. The interviews lasted about 35 minutes and were conducted in Spring, 2019. All interviews were recorded and then transcribed.

\section{Data Analysis}

The interviews were analyzed using qualitative content analysis (Graneheim and Lundman, 2004) and interpreted in the light of the theoretical framework on teacher beliefs regarding the purposes of assessment suggested by Brown (2008) and the TPB (Ajzen, 2005).

A phrase, sentence, or paragraph in the data, which conveyed the holistic meaning and was consistent with the research questions, was defined as a meaningful unit. The analysis process took place through several steps:

- The transcribed text was carefully read and repeatedly reread while identifying all meaningful units (teachers' statements directly related to the research questions);

- Based on meaningful units, repeated coding was performed to ensure the quality of the study, after which the codes were categorized and sub-categorized;

- The categories were directly derived from the theoretical framework, while sub-categories and codes were derived from the data;

- The classification of codes into categories and subcategories was repeatedly discussed with experts in the science teacher education field, changes being made to the code classification where appropriate.

The responses to the first interview question were mostly categorized to answer RQ1, while responses of the second interview question answered either the RQ1 or RQ2, depending on content, and responses to the third also answered RQ2.

As both research questions were not entirely mutually exclusive being somewhat complementary, the distinction was made between the codes, based on whether the teacher talked about CBSeT feedback, particularly the purpose of this information (which was related to the RQ1), or about $\mathrm{CBSeT}$ and promoted competences more generally (RQ2). Some codes were used twice, as they fitted equally to both RQs. For example, the code "it is complete nonsense" was categorized as an "irrelevant" purpose of CBSeT, but also as a negative attitude toward $\mathrm{CBSeT}$ and promoting competences generally. This was because, based on the teacher's statements and further discussion, it was not possible to distinguish between the two. An example of coding and its respective 
categorization, related to the meaningful unit, was as given below noting that:

For such tasks, there would be a need for student training in these skills so that students can undertake these tasks in an e-environment.

$\rightarrow$ Code: "Need for an e-repository of tasks for training students"

$\rightarrow$ Sub-category: "Lack of supportive materials"

$\rightarrow$ Category: "Perceived behavioral control beliefs" (RQ2).

Based on an assumption that the type of information a teacher perceives as relevant and gains from the feedback, reflects tacitly beliefs about the purpose(s) of assessment, teacher responses were categorized according to Brown's (2008) theoretical framework on the purposes of assessment (Table 2).

\section{Improving Teaching and Learning}

Most teachers (T1-T4, T6, T8, and T9) said that CBSeT feedback provided adequate information about the actual student level of knowledge and skills. They identified that a table describing each level provided useful information, enabling them to appreciate the knowledge and skills to which they should pay more attention, for example, they recognized they should provide students with more practice in problemsolving (T3 and T9), inquiry skills (T6), or reasoning skills (T6 and T8). Teachers T2, T3, and T8, on the other hand, did not think CBSeT feedback provided information about students' acquisition of content knowledge of a particular science subject. As T2 commented:

[CBSeT] feedback does not say anything about whether a student responded well to chemistry or physics questions.

Several teachers (T1, T6, and T8-T10) said that if they saw the actual test items, they could understand better what was required of students and as a result, they would be better able to develop the expected competences in their teaching. Two teachers (T7 and T8) commented that they felt a need for examples to be provided to understand the meaning of each competence level.

\section{Make Schools and Teachers Accountable for Their Effectiveness}

Two teachers (T6 and T8) believed that CBSeT feedback provided information about themselves, that is, how well, or poorly, they taught and whether they dealt sufficiently with a topic. Four teachers (T2, T4, T6, and T8) would have liked to see the results of other schools in CBSeT feedback, or alternatively, the average results of the country, which would have given them an indication about their own teaching quality.

Perhaps justifiably, the remaining three teachers (T1, T6, and T8) considered that students' results did not depend only on their own teaching - it was a shared responsibility. In support of this, they stated that most competences measured were common to all science subjects.

I am not responsible for this [CBSeT results] alone; there are several teachers involved here. (T6)

\section{Make Students Accountable for Their Learning}

According to four teachers (T1, T6-T8), CBSeT feedback did not give enough information about on which level (how "good" or "bad") a particular student was, compared with others in his/ her class. Relatedly, it was also difficult to explain to parents the learning of their child compared to other children, based on the received feedback (T8).

Three teachers (T1, T3, and T4) were convinced that the students did not put enough effort into taking CBSeT, because they knew they would not get a grade for it. As T1 stated:

Mostly, they [students] do not learn in order to develop themselves - they learn to get a grade, which, in turn, demonstrates their l the subject, and if the grade is "five" [highest grade in Estonia], their parents think everything is fine.

\section{Table 2: Teacher beliefs about the purposes of CBSeT feedback}

\begin{tabular}{lll}
\hline Category & Sub-category & Responses by teachers \\
\hline Improving teaching and learning & $\begin{array}{l}\text { Information indicating student level of } \\
\text { achievement }\end{array}$ & $\begin{array}{l}\text { Shows the actual level (T1, T2, T3, T4, T6, T8, T9). } \\
\text { Does not show the tasks determining the level } \\
\text { (T1, T6, T8, T9, T10). } \\
\text { Does not provide subject-specific information (T2, T3, T8, T11). } \\
\text { Provides guidelines for the next step (T4, T8). }\end{array}$ \\
& $\begin{array}{l}\text { Guidelines for subsequent teaching } \\
\text { Indicates which tasks should be designed for students (T1, T3, T2). } \\
\text { Informs about concrete competences that students need to develop } \\
\text { (T3, T6, T7, T8, T9). }\end{array}$ \\
$\begin{array}{ll}\text { Making schools and teachers } \\
\text { accountable for their teaching }\end{array}$ & $\begin{array}{l}\text { Indicates my appropriateness as a teacher (T6, T8). } \\
\text { Does not enable comparison with other schools (T2, T4, T6, T8). } \\
\text { Other teachers also share some of the responsibility (T1, T6, T8). } \\
\text { Daking students' accountable for }\end{array}$ & $\begin{array}{l}\text { Does not enable comparison between students (T1, T6, T7, T8). } \\
\text { Students are only motivated to learn for the exam or the grades awarded } \\
\text { (T1, T3, T4). } \\
\text { It is complete nonsense (T5). }\end{array}$ \\
Seeing such assessment as irrelevant &
\end{tabular}

CBSeT: Competence-based, science e-testing 
Thus, some teachers believed that (the assessment information from) CBSeT did not make students accountable for their own learning and a conventional examination/grading would be more appropriate to increase responsibility.

\section{Such an Assessment is Irrelevant}

While most teachers commented on the purposes of CBSeT assessment, one teacher (T5) did not consider such an assessment was necessary, as she felt that it interfered with her teaching. Teacher 5 argued that the electronic assessment tool was not a suitable environment for assessment and did not develop scientific knowledge in the student.

To answer the second research question "What beliefs do teachers hold about $\mathrm{CBSeT}$ and the development of wider scientific competences promoted by CBSeT?" teachers' responses and their respective codes related to this question were categorized following the three TPB belief components (Ajzen, 2005), as shown in Table 3.

\section{Attitudinal Beliefs}

Positive attitudes

Almost all teachers (T1-T4, T6-T9) were positive toward CBSeT and the development of the indicated competences. CBSeT was considered to facilitate teaching, for example, understand better the specific skills required to achieve a specific competence (T6 and T7). T7 stated that CBSeT helped her to develop as a teacher. According to two teachers (T3 and T9), who had assessed students' open-ended responses within a previous pilot for CBSeT, the tasks were innovative, related to every-day life and therefore useful for students in their understanding of the world in general, as well as necessary to be used in the context of a specific subject.

Table 3: Teachers' beliefs about CBSeT and the development of wider scientific competences

\begin{tabular}{ll}
\hline Category & Sub-category \\
\hline Attitudinal beliefs & Positive attitudes
\end{tabular}

Negative attitudes

Subjective (normative) Lack of support from colleagues beliefs

A lack of support materials

Students' abilities

A lack of teachers' practical knowledge and skills

Existence of teacher's practical knowledge and skills

Lack of time
Responses by teachers

It is necessary to develop science competences (T3, T2, T8 T9)

Innovative approaches (T4)

Also develops the teacher (T7, T8)

Increases awareness about competences $(\mathrm{T} 6, \mathrm{~T} 7)$

Tasks related to every-day life (T3, T9)

Tasks could be used in the classroom (T3, T9)

More important to know the facts (T1)

The CBSeT is complete nonsense (T5)

No need for one additional assessment tool (T10)

Won't use this information (T11)

Difficult to work with colleagues (T7, T4)

Perceive older colleagues would not use it (T4)

Lack of support for conducting inquiry learning (T6)

Exemplary tasks to practice (T1, T2, T3 T8, T9, T10)

Need for an e-repository of tasks for training students (T3, T6)

Workbooks and textbooks should contain respective tasks and activities for inquiry-based learning (T5)

Low level of students (T2, T4, T8)

Only best students are capable (T3)

Many children with special needs (T6)

Teaching is based on how smart students are (T11)

Some students' have bad reasoning skills (T8)

Such tasks are difficult to design (T2, T6, T5)

Lack of skills (T6)

Need for instruction and training (T1, T6, T9)

Own teaching already supporting some competences (T6, T8)

Students plan experiments themselves (T1)

Students are looking for answers to their questions (T6)

Undertaking group work (T6, T10)

Providing descriptive feedback to students (T7)

Organizing discussions (T6, T8)

Designing of such tasks takes time (T2, T3)

There is only time to teach the basic knowledge (T5, T7, T10)

Only have time for teacher monologue (T10)

Preparing for the exam takes most of the time (T1, T7)

Overloaded syllabus does not provide time to develop

competences (T7, T11) 
In general, younger teachers (T4, T7, and T9) seemed more open to CBSeT:

As a young teacher, I liked such innovative things [like CBSeT], I liked to experiment. (T4)

\section{Negative attitudes}

A few teachers (T1, T5, T10, and T11) were rather negative toward CBSeT. According to T5, the expected skills were not age appropriate and some skills (e.g., data analysis and social dimensions) should not be taught by science teachers.

In biology, it is more important to teach "flora and fauna." [...] As a biologist, I see that this [CBSeT] is all nonsense. I want them [my students] to know the trees and bushes and listen to the birdsong. (T5)

Teacher T1 emphasized the importance of students knowing facts, as it helped them to make better connections. According to teacher T10, such additional assessment tools (as CBSeT) would require extra energy from him and will reduce his motivation to deal with it since too many additional skills needed to be developed and assessed.

\section{Subjective (Normative) Beliefs}

Three teachers (T4, T6, and T7) felt that they were not getting enough support from their (older) colleagues. A young teacher (T4) predicted that her older colleagues would probably not engage in developing such competences in the classroom. Another young teacher (T7) admitted that picking up novel and different approaches would be rather difficult, or even impossible, with her current colleagues, which in turn affected her own motivation to innovate:

I feel it would be exciting to do an interdisciplinary project... but my colleagues are not interested in doing such things,...This affects my motivation, which just disappears.

\section{Perceived Behavioral Control Beliefs}

Many teachers had positive attitudes toward CBSeT and the need to develop a wide spectrum of student competences in science lessons. Nevertheless, most teachers, including those having a positive attitude, tended to be sceptical about applying the assessment information obtained from CBSeT to improve their students' competences in their own practice.

\section{A lack of support materials}

One of the main reasons cited by teachers (T1-T3, T8-T10) for not focusing on teaching competencies was the lack of corresponding teaching materials. Two teachers (T2 and T5) emphasized the existing teaching materials, such as textbooks and workbooks, were guiding their everyday teaching, indicating these were easy to use, contained all necessary key concepts, and were an authoritative source of knowledge. Thus, T2 and T5 expected the new textand workbooks to go beyond knowledge and skills and devote more space to the development of the competences highlighted in CBSeT from now on. For one teacher (T3), it was important to "train" such competences through specific tasks. Furthermore, a lack of relevant on-line materials was signaled by $\mathrm{T} 2$ and $\mathrm{T} 6$.

\section{Lack of time}

Seven teachers (T1-T3, T5, T7, T10, T11) pointed out the lack of time to develop student competences, which they believed was due to the extensive subject syllabus, time required in preparation for exams and subject competitions for talented students. Such arrangements did not leave time and freedom to develop all required competences in their opinion. Teacher 10 highlighted:

If the syllabus was half of the existing - if someone had the courage to throw out half of the things ... then there would be time to discuss and experiment.

\section{Students' ability}

Six teachers (T2-T4, T6, T8, and T11) stated that if there were predominantly less capable students in the classroom, it was difficult and undesirable to promote and seek to achieve all the competences listed in CBSeT. Teacher 11 stated:

I can hardly teach the content that is given in the syllabus because my students are not very capable.

Teachers (T2-T4, T8, and T11) went as far as to state that the tasks and activities targeting wider scientific competences are rather meant for "smart kid" and according to T3:

For the less capable perhaps, it is important to teach basic knowledge primarily.

\section{Teachers' lack of practical knowledge and skills}

In addition to the lack of support materials, lesson time, and students' abilities, a number of teachers (T1, T2, T3, T5, T6, and T9) also pointed out their own limited knowledge and skills for developing such competences in the classroom.

Probably, I am not able to develop this competence [how to solve problems]... so I have to make up problems to develop the skill. I have never been thinking like that - if I want to develop these competences, I should understand their essence. (T3)

Three teachers (T1, T6, and T9) recognized the need to participate in an in-service course to gain practical knowledge about how to better apply the assessment information from science CBSeT feedback in their teaching. This, naturally, required extra time from them.

\section{Existence of teachers' practical knowledge and skills}

Some teachers (T6 and $\mathrm{T} 8$ ) received confirmation from the feedback that their own teaching approach was already supporting the development of many of the required competences, and thus they felt they had been doing "the right thing" (T6). According to teachers T1, T6-T8, and T10, they used student-centered teaching methods, such as studentcentered experimentation (T1 and T6), group work (T6 and T10) and student presentations (T6), inter-active discussions (T8), and provided descriptive feedback to students (T7) from time to time. Teacher 8 pointed out: 
I have solved problems related to GMOs with students and they have been debating its acceptability. First, the students study the topic, and then there is a debate.

\section{DISCUSSION}

The aim of this study was to recognize the extent to which teachers' existing beliefs toward CBSeT enabled them to use the received feedback in their practice thus promoting wider scientific competences in students. Furthermore, information gained from this study was seen as providing science teachers in Estonia with relevant support through addressing their specific constraints/needs related to the change of approach.

Teachers' Beliefs about the Purposes of CBSeT Feedback Based on the findings, all four purposes of assessment presented by Brown (2008) were evident in Estonian science teachers' beliefs about CBSeT.

The general teacher belief that feedback from CBSeT provided relevant information, about which student competences to improve, was very much in accordance with the main purpose of assessment, as stated in the Estonian national curriculum (Ministry of Education and Research, 2014a). This was seen as supporting students' individual development and empowers their learning potential. However, some teachers expected to receive more subject-specific information from CBSeT feedback to know exactly what science knowledge should receive more attention in the future. Not only was such a purpose incorrect, it would not have been technically possible to generate, automatically, a very specific, and at the same time, reliable feedback about the acquisition of content knowledge in each science subject separately. Based on this, it seemed important to provide more clarification with regard to the goal of CBSeT. Furthermore, this finding confirmed that from other studies (Henno et al., 2017; Kask, 2009) in which science teachers perceived the need to teach content rather than paying attention to wider competences.

Notwithstanding the fact that most teachers identified with the purposes of assessment from CBSeT feedback being related to student learning improvement, a more dominant belief related to accountability. In this respect, most teachers felt it was very important for them to get comparative information from the feedback, that is, how the student/group of students in their school compared with others. This finding was similar to that from a study by Brown and Harris (2009), who found accountability strongly dominating over the purpose of improvement. According to Brown et al. (2019), this was the case even though educational policies in many countries had strongly advocated assessment for improvement (as is the case in Estonia). The strength of the teacher belief on the importance of accountability might be attributed to the fact that in Estonia, and beyond, external assessment had, for years, put more emphasis on final scores than on identifying levels of students' actual competence and learning needs (Brown and Harris, 2009).
According to some teachers, students did not put enough effort in undertaking CBSeT, because no grade was given, plus there was no comparison between students. Thus, some teachers believed that CBSeT did not make students responsible (accountable) for their own learning. This gave the impression, that for these teachers, grades were the only motivator to initiate student learning. Furthermore, it could be speculated that these teachers did not recognize the power of formative assessment in making learning more self-regulated and meaningful for students (Black and Wiliam, 2009).

At least one teacher perceived the assessment of scientific competences as pointless, as it was probably perceived as not being in line with her beliefs and long-term teaching practices. This suggested that there was still a gap in teachers' understanding of the competency-based direction in the current curriculum.

Teachers' Beliefs about CBSeT and the Development of Wider Scientific Competences Promoted by the Test

Teachers' beliefs were considered, based on each TPB belief category (attitudinal beliefs, subjective/normative beliefs, perceived behavioral control beliefs) (Ajzen, 2005).

More than half the teachers indicated a positive attitude toward $\mathrm{CBSeT}$ and the promoted competences, for example, seeing the approach as innovative and the development of competences as really important in teaching science. In some cases, CBSeT with respective feedback was seen as aiding better insights into the competences themselves. Furthermore, some teachers held supposedly negative beliefs, which were in conflict with the conception of CBSeT and who did not see the need for "one additional assessment tool" seeing this as taking too much energy from the teacher, or taking away the time and focus from teaching the facts, which according to Chen et al. (2012), Fives et al. (2015), and Trigwell (2012) typified a teaching beliefs of a teacher-centered nature.

Three teachers who expressed rather positive attitudinal belief toward CBSeT perceived that they were not supported by other teachers who, in their opinion, lacked enthusiasm for developing competency-based skills in students. Two out of the three younger teachers indicated that they felt negative support from their older colleagues. Ajzen (2005) suggested such negative normative beliefs had a counterproductive impact on their intention and actual teaching in the classroom toward developing broader scientific competences in students.

Many teachers saw a number of limitations (negative perceived behavioral control beliefs) in using the assessment information they received. The teachers stated four main reasons for this:

a. A lack of practical knowledge and skills. Although student-centered approaches were prevalent in most science teacher in-service provisions in Estonia, these might have been too short-term or random for these teachers in challenging their strongly held belief system. Based on findings by the Vaino et al. (2013) and Henno et al. (2017), changes in beliefs took time, 
as emerging positive beliefs supporting, for example, a more competence driven approach, needed to be tested in practice, or within longer teacher professional development programs, which helped to strengthen teacher's self-efficacy in student-centered approaches in teaching (Buldur, 2016; Markic and Eilks, 2013)

b. A lack of supportive materials, for example, providing guidance, exemplary tasks, and ready-made teaching materials for developing specific competences. Some teachers strongly emphasized the "training" aspect, even if using ready-made competence-promoting teaching materials. This indicated that even in seeking to promote competences, they tended to take a teacher-centered stance, for which their main aim was not so much to improve students' competences generally, but rather to train specific skills so as to enable better results from the next CBSeT

c. Student ability. Almost half the teachers pointed out that the low ability of students prevented them from teaching competence-based skills in science. This suggested that teachers, themselves, were hiding their incompetence in that they did not know how exactly to guide their students. It also related to remarks in the teacher interviews that such teachers did not actually have the conceptualization for developing competences. This re-enforced a belief that such teachers were not appreciating the educational focus of the Estonian national curriculum (Ministry of Education and Research, 2014a) and continued to emphasize content driven approaches in teaching and assessment

d. A lack of classroom and planning time, because of overloaded subject syllabi, and/or preparation for an examination or subject Olympiad. Lack of time was the most frequent complaint from teachers, especially if it concerned student-centered approaches in teaching. This belief impeded the extensive use, in science teaching, of, for example, inquiry-based learning (Kask, 2009), constructivist teaching approaches (Haney and McArthur, 2002), or strategies for promoting scientific literacy in students (Vaino et al., 2013), these seen as taking more lesson time than giving a lecture (teacher monologue). As external assessments (e.g., examinations), tended to have a narrow focus, assessing only students' particular knowledge and skills (Jones and Egley, 2004) and not wider competences, teachers might feel highly pressured when trying to implement an innovative approach in which they did not believe (Haney and McArthur, 2002; Vaino et al., 2013). Bryan (2012), based on her literature review, found that these factors influenced teachers, even to the point that they simply resisted thinking and teaching in any alternative way to that already operative.

In spite of several negative control beliefs (time, support materials) and subjective/normative beliefs (lack of support from colleagues), some teachers felt their existing practice was already associated with a competence-based science learning approach and thus had familiarity with the needed knowledge and skills. Such teachers were satisfied that CBSeT validated their existing approach. However, the current study indicated, as did finding by Chen and Brown (2016) and Verjovsky and Waldegg (2005), that teachers may hold simultaneously both teacher-centered and student-centered beliefs, which, in the current context, could be illustrated by teacher believing that CBSeT feedback provides useful information about the next steps to be taken to improve students' learning (expressing the formative purpose of CBSeT and indicates student-centered character) and that students are only motivated to take an examination (which assumes the teacher felt there was no other incentives to motivate students except grades).

It is suggested, therefore, that the assessment information from $\mathrm{CBSeT}$ does not yet serve the purpose, that is, to support teaching and learning (Bennett, 2011; Brown et al., 2014; Harlen, 2005). These findings are somehow understandable, as most of the interviewed teachers have long teaching experience, during which firm beliefs about teaching and assessment methods have become part of their identity (Jones and Carter, 2007; Pajares, 1992). Fortunately, previous research has also shown that change can be fostered through long-term practical training development programs consciously taking into account teachers' existing beliefs (Bryan, 2012; Buldur, 2016; Markic and Eilks, 2013). Based on findings by Vaino et al. (2013) and Henno et al. (2017), changes in beliefs take time, as emerging positive beliefs supporting, for example, a more competence driven approach, need to be tested in practice or within longer teacher professional development programs.

Based on the theoretical framework suggested by Brown (2008), and the TPB (Ajzen, 2005), three distinguishable groups of teachers could theoretically be identified from the data:

(1) Teachers with positive attitudes toward CBSeT and related competences, believing in the improvement function of such testing, with no major constraints (negative PBC and $\mathrm{SN}$ beliefs). Such teachers possess both the willingness and skill to use the feedback purposefully in practice to raise students' scientific competences

(2) Teachers with positive attitudes, believing (at least to some extent) in the improvement feedback purpose of $\mathrm{CBSeT}$, but recognizing a number of constraints (negative PBC and SN beliefs), for example, the will, but not possessing all skills, and probably having difficulties in implementing the feedback in practice

(3) Teachers with a negative attitude, not believing in the improvement, but rather the accountability function of CBSeT, with major negative PBC and SN beliefs who cannot be expected to use the feedback for improving their teaching and students' learning toward wide spectrum scientific competences.

Findings indicated that there were no teachers in hypothetical group 1, while more than half of the teachers could be placed in the second group, and three teachers were associated with the last group. 
It could be suggested that the $2^{\text {nd }}$ group could be the target group for future in-service, professional development courses as their willingness to act were mainly held back by their own lack of knowledge. It could be seen as skills and/or resources available - aspects that could be changed through teacher inservice program, unlike students' abilities.

\section{RECOMMENDATIONS}

Based on the findings and the assumption that the current sample represents a quite characteristic snapshot of the science teachers in Estonia, it is recommended that to support teachers in the uptake of CBSeT, information for enhancing students' broader scientific competences, any teacher in-service program (long-term, preferably) needs to:

1. Develop a clearer understanding among teachers of the wider scientific competences, taking into account their existing knowledge and skills

2. Be made more aware of the opportunities that are embedded in CBSeT feedback, and encourage the use of this information, for example, for identifying learning gaps of their students and for getting broader insights into what could be done as a next step in the classroom, that CBSeT acts, in the long run, as assessment for learning

3. Enrich teachers' personal toolkit with innovative methods, including assessment strategies that focus on improvement of broader scientific competences through practical activities

4. Generate an atmosphere of close collaboration and collegial support in the course of a professional development program, especially important for those teachers who lack support within their own school. For the same purpose, whenever possible, to involve at least two teachers, and in the best case, a school authority from the same school to take part in the program, helping to strengthen and maintain each other's expectedly positive, yet tentative, beliefs, toward the new teaching and assessment approaches.

With respect to the feedback format, it is proposed that:

1. This is complemented by suggested teaching methods suited to develop particular competences. For that, all existing resources are reviewed with appropriate methods selected and added into an online resource repository

2. Teachers and students are equipped with exemplary tasks, illustrating the essence of a particular competence that is assessed in CBSeT to increase teachers' and students' awareness of, confidence in, and trust toward, CBSeT.

\section{ACKNOWLEDGMENTS}

This work was supported by the Estonian Research Council grant (MOBTP81) and Foundation Innove. The authors are very thankful to the teachers who devoted their time and participated in the study.

\section{REFERENCES}

Ajzen, I. (1991). The theory of planned behavior. Organizational Behavior and Human Decision Processes, 50, 179-211.

Ajzen, I. (2005). Attitudes, Personality and Behavior. $2^{\text {nd }}$ ed. Chennai: Open University Press.

Ajzen, I. (2011). The theory of planned behavior: Reactions and reflections. Psychology and Health, 26(9), 1113-1127.

Alt, D. (2018). Teachers' practices in science learning environments and their use of formative and summative assessment tasks. Learning Environ Research, 21(3), 387-406.

Bandura, A. (1993). Perceived self-efficacy in cognitive development and functioning. Educational Psychologist, 28, 117-148.

Barnes, N., Fives, H., \& Dacey, C.M. (2015). Teachers' beliefs about assessment. In: Fives, H., \& Gill, G., (Eds.), International Handbook of Research on Teacher Beliefs. London: Routledge. pp. 284-300.

Beck, J., Czerniak, C.M., \& Lumpe, A.T. (2000). An exploratory study of teachers' beliefs regarding the implementation of constructivism in their classrooms. Journal of Science Teacher Education, 11(4), 323-343.

Bennett, R.E. (2011). Formative assessment: A critical review. Assessment in Education: Principles, Policy and Practice, 18(1), 5-25.

Biggs, J.B. (1995). Assumptions underlying new approaches to educational assessment. Curriculum Forum, 4(2), 1-22.

Black, P. (2000). Research and the development of educational assessment. Oxford Review of Education, 26(3/4), 407-419.

Black, P., \& Wiliam, D. (2009). Developing the theory of formative assessment. Educational Assessment, Evaluation and Accountability, 21(1), 5-31.

Bonner, S.M. (2016). Teachers' perceptions about assessment: Competing narratives. In: Brown, G.T.L., \& Harris, L.R., (Eds.), Handbook of Human and Social Conditions in Assessment. London: Routledge. pp. 21-39.

Brookhart, S.M. (2010). How to Asses Higher-Order Thinking Skills in Your Classroom. United States: ASCD.

Brown, G.T.L. (2004). Teachers' conceptions of assessment: Implications for policy and professional development. Assessment in Education: Principles, Policy and Practice, 11(3), 301-318.

Brown, G.T.L. (2008). Conceptions of Assessment: Understanding what Assessment Means to Teachers and Students. United States: Nova Science Publishers.

Brown, G.T.L. (2016). Improvement and accountability functions of assessment: Impact on teachers' thinking and action. In: Peters, A.M., (Ed.), Encyclopedia of Educational Philosophy and Theory. Germany: Springer. pp. 1-6.

Brown, G.T.L. (2017). Assessment of Student Achievement. London: Routledge.

Brown, G.T.L., \& Harris, L.R. (2009). Unintended consequences of using tests to improve learning: How improvement-oriented resources heighten conceptions of assessment as school accountability. Journal of Multi-Disciplinary Evaluation, 6(12), 68-91.

Brown, G.T.L., Gebril, A., \& Michaelides, M.P. (2019). Teachers' conceptions of assessment: A global phenomenon or a global localism. Frontiers in Education, 4(16), 1-13.

Brown, L.I., Bristol, L., Four-Bab, J.D., \& Conrad, D.A. (2014). National tests and diagnostic feedback: What say teachers in Trinidad and Tobago? The Journal of Educational Research, 107(3), 241-251.

Bryan, L.A. (2012). Research on science teacher beliefs. In: Fraser, B., Tobin, K., \& McRobbie, C., (Eds.), Second International Handbook of Science Education. Germany: Springer. pp. 479-495.

Buldur, S. (2016). A longitudinal investigation of the preservice science teachers' beliefs about science teaching during a science teacher training programme. International Journal of Science Education, 39(1), 1-19.

Chen, J., \& Brown, G.T.L. (2016). Tension between knowledge transmission and student-focused teaching approaches to assessment purposes: Helping students improve through transmission. Teachers and Teaching, Theory and Practice, 22(3), 250-367.

Chen, J., Brown, G.T.L., Hattie, J.A., \& Millward, P. (2012). Teachers' conceptions of excellent teaching and its relationships with self-reported teaching practices. Teaching and Teacher Education, 28, 936-947.

Cizek, G.J. (2010). An introduction to formative assessment (history, 
characteristics, and challenges). In: Andrade, H., \& Cizek, C.J., (Eds.), Handbook of Formative Assessment. London: Routledge. pp. 3-16.

Duru, S. (2015). A metaphor analysis of elementary student teachers' conceptions of teachers in student-and teacher-centered contexts. Eurasian Journal of Educational Research, 60, 281-300.

Fives, H., \& Buehl, M.M. (2012). Spring cleaning for the 'messy' construct of teachers' beliefs: What are they? Which have been examined? What can they tell us? In: Harris, K.R., Graham, S., \& Urdan, T., (Eds.), APA Educational Psychology Handbook: Individual Differences and Cultural and Contextual Factors. United States: American Psychological Association. pp. 471-499.

Fives, H., Lacatena, N., \& Gerard, L. (2015). Teachers' beliefs about teaching (and learning). In: Fives, H., \& Gill, M.G., (Eds.), International Handbook of Research on Teachers' Beliefs. London: Routledge. pp. 149-265.

Goodson, I., Moore, S., \& Hargreaves, A. (2006). Teacher nostalgia and the sustainability of reform: The generation and degeneration of teachers' missions, memory, and meaning. Educational Administration Quarterly, $42(1), 42-61$.

Graneheim, U.H., \& Lundman, B. (2004). Qualitative content analysis in nursing research: Concepts, procedures and measures to achieve trustworthiness. Nurse Education Today, 24, 105-112.

Haney, J., \& McArthur, J. (2002). Four case studies of prospective science teachers' beliefs concerning constructivist teaching practices. Science Education, 86, 783-802.

Harlen, W. (2005). Teachers' summative practices and assessment for learningtensions and synergies. The Curriculum Journal, 16(2), 207-223.

Harlen, W. (2012). On the relationship between assessment for formative and summative purpose. In: Gardner, J., (Ed.), Assessment and Learning. United States: SAGE. pp. 87-102.

Harlen, W., \& James, M. (1997). Assessment and learning: Differences and relationships between formative and summative assessment. Assessment in Education: Principles, Policy and Practice, 4(3), 365-379.

Hattie, J., \& Timperley, H. (2007). The power of feedback. Review of Educational Research, 77(1), 81-112.

Henno, I., Kollo, L., \& Mikser, R. (2017). Eesti loodusainete õpetajate uskumused, õpetamispraktika ja enesetõhusus TALIS 2008 ja 2013 uuringu alusel [Estonian science teachers' pedagogical beliefs, teaching practices and self-efficacy based on the results of the TALIS 2008 and 2013 reports]. Estonian Journal of Education, 5(1), 268-296.

Heuckmann, B., Hammann, M., \& Asshoff, R. (2020). Identifying predictors of teachers' intention and willingness to teach about cancer by using direct and belief-based measures in the context of the theory of planned behaviour. International Journal of Science Education, 42(4), 547-575.

Jamalzadeh, M., \& Shahsavarb, Z. (2015). The Effects of contextual factors on teacher's beliefs and practices. Procedia-Social and Behavioral Sciences, 192, 166-171.

Jones, B.D., \& Egley, R.J. (2004). Voices from the frontlines: Teachers' perceptions of high-stakes testing. Education Policy Analysis Archives, 12(39), 1-34. Available from: http://www.epaa.asu.edu/epaa/ v12n39.

Jones, M.G., \& Carter, G. (2007). Science teacher attitudes and beliefs. In: Abell, S.K., \& Lederman, N.G., (Eds.), Handbook of Research on Science Education. United States: Lawrence Erlbaum Associates. pp. 1067-1104.

Kask, K. (2009). A Study of Science Teacher Development towards Open Inquiry Teaching through an Intervention Programme, Doctoral Dissertation. Tartu: University of Tartu Press.

Khan, E.A. (2000). A case study of assessment in a grade 10 English course. The Journal of Educational Research, 93, 276-286.

Kutluca, A.Y., \& Aydin, A. (2016). An examination of prospective elementary Science teachers' perspective towards socio-scientific argumentation. Science Education International, 27(3), 320-343.

Kynigos, C., \& Argyris, M. (2004). Teacher beliefs and practices formed during an innovation with computer-based exploratory mathematics in the classroom. Teachers and Teaching, 10(3), 247-273.

Levitt, K.E. (2002). An analysis of elementary teachers' beliefs regarding the teaching and learning of science. Science Education, 86(1), 1-22.

Markic, S., \& Eilks, I. (2013). Potential changes in prospective chemistry teachers' beliefs about teaching and learning-a cross-level study. International Journal of Science and Mathematics Education, 11, 979-998.

Ministry of Education and Research. (2014a). National Curricula 2014. Available from: https://www.hm.ee/en/national-curricula-2014.

Ministry of Education and Research. (2014b). The Estonian Lifelong Learning Strategy 2020 Available from: https://www.hm.ee/sites/ default/files/estonian_lifelong_strategy.pdf.

Newton, P.E. (2007). Clarifying the purposes of educational assessment. Assessment in Education: Principles, Policy and Practice, 14(2), 149-170.

Pajares, M.F. (1992). Teachers' beliefs and educational research: Cleaning up a messy construct. Review of Educational Research, 62(3), 307-332.

Qureshi, S., Bradley, K., Vishnumolakala, V.R., Treagust, D.F., Southam D.C., Mocerino, M., \& Ojeil, J. (2016). Educational reforms and implementation of student-centered active learning in science at secondary and university levels in Qatar. Science Education International, 27(3), 437-456.

Rannikmäe, M., Soobard, R., Reiska, P., Rannikmäe, A., \& Holbrook, J. (2017). Õpilaste loodusteadusliku kirjaoskuse tasemete muutus gümnaasiumiõpingute jooksul [The change in student scientific literacy levels during gymnasium studies]. Estonian Journal of Education, 5(1), 59-98.

Rannikmäe, M., Vaino, K., Soobard, R., Rosin, T., Teppo, M., \& Must, O. (2019). Loodusvaldkonna Õpitulemuste Hindamine III-IV Kooliastme, Raport [Assessment of Science Learning Outcomes: Lover and Upper Secondary School Levels], Tartu.

Roberts, D.A., \& Bybee, R.W. (2014). Scientific literacy, science literacy, and science education. In: Lederman, N.G., \& Abell, S.K., (Eds.), Handbook of Research on Science Education. Vol. 3. London: Routledge. pp. 545-558.

Roberts, R., Baker, M.A., \& Goossen, C.E. (2016). The chasm between beliefs and practice: A case study of the epistemological positions of pre-service agricultural education teachers. Journal of Agricultural Education, 57(2), 172-186.

Sadler, D.R. (2010). Beyond feedback: Developing student capability in complex appraisal. Assessment and Evaluation in Higher Education, 35(5), 535-550.

Sak, R., Tankeking-Erden, F., \& Morrison, G.S. (2018). Preschool teachers' beliefs and practices related to child-centred education in Turkey. International Journal of Primary, Elementary and Early Years, 46(5), 563-577.

Shute, V.J. (2008). Focus on formative feedback. Review of Educational Research, 78(1), 153-189.

Title, C.K. (1994). Toward an educational psychology of assessment for teaching and learning: Theories, contexts, and validation arguments. Educational Psychologist, 29, 149-162.

Trigwell, K. (2012). Relation between teachers' emotion in teaching and their approaches to teaching in higher education. Instructional Science, 40, 607-621.

Vaino, K., Holbrook, J., \& Rannikäe, M. (2013). A case study examining change in teacher beliefs trough collaborative action research. International Journal of Science Education, 35(1), 1-30.

Verjovsky, J., \& Waldegg, G. (2005). Analyzing beliefs and practices of a Mexican high school biology teacher. Journal of Research in Science Teaching, 42(4), 465-491.

Wallace, C.S., \& Kang, N.H. (2004). An investigation of experienced secondary science teachers' beliefs about inquiry: An examination of competing belief sets. Journal of Research in Science Teaching, 41(9), 936-960.

Xiao, Y. (2017). Formative assessment in a test-dominated context: How test practice can become more productive. Language Assessment Quarterly, 14(4), 295-311.

Zembylas, M. (2005). Beyond teacher cognition and teacher beliefs: The value of the ethnography of emotions in teaching. International Journal of Qualitative Studies in Education, 18(4), 465-487. 


\section{APPENDIX}

\section{Appendix 1: Example of a CBSeT feedback form}

The student is able

\section{Scientific content}

\begin{tabular}{ll}
\hline Baseline & To identify an explanation of a scientific phenomenon; - to identify scientific statements, definitions, units, and symbols; - to \\
& supplement a scientific model (e.g., add knowledge dimensions to a drawing). \\
Average & To explain a scientific phenomenon, pointing out cause and effect relationships; - to use correctly scientific terms, units, or \\
& symbols; - to explain a scientific model. \\
- & To explain a scientific phenomenon presented in an interdisciplinary context (a natural phenomenon related to life, \\
& identifying cause and effect relationships); \\
High-level & To utilize correctly complicated scientific notations, units or representations (e.g., convert units and undertake calculations \\
& based on a given relationship); \\
- & To devise a scientific model.
\end{tabular}

\section{Excellence}

\section{Inquiry skills}

Baseline $\quad$ - To identify the appropriate wording of a problem in everyday situations; - to identify a suitable scientific question/
hypothesis in the given situation; - to identify experimental tools/activities provided to solve a problem with a scientific
content; - to perform simple data analysis, using data from a chart or table.
- To formulate an inquiry procedure on the basis of an everyday situation;
- To formulate a research question/hypothesis based on a given situation;
- To design an experiment to solve an inquiry with a scientific content, selecting appropriate apparatus and procedures and
justifying these;
- To perform data analysis and make conclusions using data from a diagram, chart, or table.
- To formulate a society-related scientific inquiry, based on a given situation;
- To formulate and justify the research question/hypothesis in the given situation;
- To design an experiment to solve a scientific inquiry with a scientific content; analyze and justify the experimental design
chosen (including use of a control, determining number of repeats, method of presentation of results);
High-level $\quad$ To undertake data analysis and make conclusions using complex data from a diagram, chart, or table.
- To formulate and justify the experimental design and procedures chosen to solve a scientific inquiry.

\section{Problem solving and decision making skills}

\begin{tabular}{|c|c|}
\hline Baseline & $\begin{array}{l}\text { - To give a solution to a scientific problem, or make a justified decision associated with an issue based on a single } \\
\text { viewpoint (e.g., to state only the scientific position in the response); }\end{array}$ \\
\hline Average & $\begin{array}{l}\text { - To justify a solution to a scientific problem based on practical graphical or tabular data (e.g., determining best straight } \\
\text { line, or calculation of means), or to make a socio-scientific decision to resolve an issue, justify this considering the relative } \\
\text { importance of two identified factors involved (e.g., to put forward a decision taking into account the scientific and also } \\
\text { another factor, e.g., economic or social or environmental perspective) }\end{array}$ \\
\hline High-level & $\begin{array}{l}\text { - To solve a complex scientific problem involving manipulation of variables, or make a socio-scientific decision to resolve } \\
\text { an issue and justify this considering the relative importance of at least three different factors involved (e.g., to put forward } \\
\text { scientific as well, at least two other perspectives from economic, environmental, social, moral, or ethical considerations) }\end{array}$ \\
\hline \multicolumn{2}{|r|}{ Excellence } \\
\hline \multicolumn{2}{|r|}{ Communication skills } \\
\hline Baseline & $\begin{array}{l}\text { - To compose a simple, short, scientific text in a familiar situation; - to find relevant everyday information on the Internet } \\
\text { using a single source }\end{array}$ \\
\hline \multirow[t]{2}{*}{ Average } & - To compose a text with a scientific content in a familiar situation, using scientific definitions; \\
\hline & - To find relevant information on the Internet using multiple sources and evaluate the reliability of the selected sources. \\
\hline \multirow[t]{2}{*}{ High-level } & - To compose a text with a scientific content in a familiar situation, correctly conceptualizing the scientific ideas; \\
\hline & - To find relevant scientific information on the Internet using multiple sources, correctly conceptualizing the scientific ideas \\
\hline Excellence & $\begin{array}{l}\text { - To compose science-based text in a novel (new) context, using science definitions correctly and demonstrating a correct } \\
\text { conceptualization of the science content }\end{array}$ \\
\hline
\end{tabular}

CBSeT: Competence-based, science e-testing 